\title{
PENINGKATAN PENDAPATAN MELALUI PENGELOLAAN BERNILAI TAMBAH PADA USAHA RUMAHAN
}

\section{INCREASES REVENUE THROUGH ADDITIONAL VALUE MANAGEMENT ON HOUSEHOLD ENTERPRISES}

\author{
${ }^{1)}$ Ida Ayu Kade Rachmawati Kusasih, ${ }^{2}$ Budi Istiyanto \\ Program Studi Manajemen Ekonomi, STIE Surakarta \\ 1)ibuadektitok@yahoo.co.id, ${ }^{2}$ budisties@gmail.com
}

\begin{abstract}
ABSTRAK
Peran seorang istri sekarang sudah mulai bergeser menjadi seorang entreprenenur. Hal ini dimulai dari usaha rumahan yang pada awalnya dilakukan untuk mengisi waktu luang setelah kewajiban pekerjaan rumah tangga selesai. Namun usaha rumahan 2 ibu-ibu (mitra) yang berada di daerah Karangduwet, Klaten dalam mengelola usaha tersebut mereka masih berorientasi sederhana hanya untuk mengisi waktu, sehingga usahanya masih belum dapat berkembang dengan baik. Pengabdian ini berupaya memberdayakan usaha rumahan tersebut untuk dapat memiliki nilai tambah yang sebelumnya hanya berjalan dengan banyak keterbatasan. Pelaksanaan program pengabdian kepada masyarakat pada mitra 1 (Arum Snack) dengan memberikan pendampingan manajemen sederhana untuk usaha rumahan yaitu pengelolaan efisiensi produksi dan pemberian alat pengrajang kacang dapat menghemat waktu membuat rajangan kacang sehingga produktivitas meningkat. Demikian juga dengan pengelolaan keuangan yang sudah memisahkan keuangan usaha dengan keluarga meskipun masih secara manual dengan menggunakan buku kas. Untuk mitra 2 (Yasmin Collection) telah memiliki blog dan facebook untuk memperluas jangkauan pemasaran online-nya. Alamat online yang dibuat dengan nama Yasmin Online Shop yang bergeser dari penjualan fashion merambah ke makanan kecil khas Klaten yang dihasilkan oleh produksi rumahan di sekitar mitra. Pemasaran sudah sampai ke luar Jawa yaitu Kalimantan meskipun dalam jumlah yang masih terbatas. Kegiatan monitoring dan evaluasi terhadap program kegiatan serta pendampingan tetap dilakukan. Penambahan brand atau merk pada produk mitra juga dilakukan agar produk dari mitra dapat lebih marketable. Pendampingan pengelolaan keuangan sederhana dilakukan agar mitra dapat mengakses pinjaman dari lembaga keuangan untuk menambah modal kerja mereka. Peningkatatan pendapatan seperti yang diinginkan dalam program kegiatan pengabdian ini tercapai pada kedua mitra. Pelaksanaan pengabdian yang telah dilakukan menyarankan agar pemerintah memberi atensi lebih dalam pengembangan usaha rumahan dengan memberikan pengetahuan tentang manajemen bisnis baik sisi produksi maupun pengelolaan administrasi agar dapat mengembangkan dan meningkatkan kemampuan usaha kecil rumahan dapat memiliki kemampuan bersaing di pasar yang akan datang.
\end{abstract}

Keyword : peningkatan pendapatan, usaha rumahan

\section{ABSTRACT}

The role of a wife has begun to shift into an entrepreneur now. This starts with a home-based business that was initially done to fill the spare time after the housekeeping duty were completed. However, the home business of 2 mothers (partners) who are in Karangduwet area, Klaten in managing the business they are still oriented simple just to fill the time, so that his business still can not develop well. This dedication seeks to empower the home-based business to be able to have added value that previously only runs with many limitations. Implementation of community service program to partner 1 (Arum Snack) by providing simple management assistance for home business that is management of production efficiency and giving of peanut maker can save time to make peanut rajangan so that productivity increase. Likewise with the financial management that has been separating business finances with the family though still manually using a cash book. For partner 2 (Yasmin Collection) already has blogs and facebook to expand its online marketing range. An online address created by the name Yasmin Online Shop that shifts from fashion sales goes to typical Klaten snacks produced by home-based 
production around partners. The products is Marketed to outside Java, especially Kalimantan although that is still limited. Monitoring and evaluation on activities and mentoring program are still done. The addition of brand on partner products is also done so that the products can be more marketable. Simple financial management assistance is done so that partners can access loans from financial institutions to increase their working capital. Increased revenue in this program is achieved on all of the partners. Implementation of the dedication that has been done to suggest that the government give more attention in the development of home business by providing knowledge about business management both production side and administrative management in order to develop and improve the ability of small home business can have the ability to compete in the future market.

Keyword : revenue increase, home business

\section{Submited : 10 April 2017 Revision : 20 Juni 2017 Accepted:9 September 2017}

\section{PENDAHULUAN}

Perkembangan Usaha Mikro Kecil dan Menengah (UMKM) di Jawa Tengah menurut data terakhir di tahun 2016 adalah berjumlah 112.550 dalam binaan Dina Koperasi dan UMKM Jawa Tengah (https://klatenkab.bps.go.id). Termasuk di dalamnya adalah UMKM di Kabupaten Klaten yang merupakan bagian dari salah satu Kota Kabupaten di Jawa Tengah yang memiliki letak yang strategis yaitu berada di tengah antara Kota Surakarta dan Kota Yogyakarta (Propinsi DIY).

Menurut data yang ada, jumlah unit usaha yang berasal dari hasil pertanian dan kehutanan di Klaten hanya merupakan sebagian dari unit usaha di Klaten, yaitu sejumlah 3,548 unit. Hal ini sangat mendukung perekonomian di Kabupaten Klaten, sehingga sangat penting bila pengelolaan dari setiap unit usaha dibuat lebih profesional dan memiliki pengelolaan yang baik sehingga dapat mendukung pendapatan dari Kabupaten tersebut.

Bentuk badan usaha dari UMKM yang ada biasanya dikelola oleh perorangan sehingga pengelolaan administrasinya kurang baik, namun jumlah UMKM tetap berkembang pesat walaupun dalam keterbatasan sumber daya manusia, keahlian, kompetensi dan manajemen (Hamdani \& Awatara, 2011). Penggunaan teknologi informasi juga sangat diperlukan dalam pengembangan UMKM (Rachman, Muhamad, Ramdani, Kunci, \& Geulis, 2016) sehingga akan dapat meningkatkan pendapatan dari unit usaha (Utari \& Dewi, 2014).

Banyak UMKM yang belum memiliki pemahaman tentang kewirausahaan sehingga mengalami kesulitan untuk berkembang dan memanfaatkan inovasi dari teknologi. Hal ini terjadai karena keterbatasan sumber daya yang dimiliki dan ketiadaan perhitungan nilai tambah yang diperoleh dari penerapan teknologi sehingga UMKM belum dapat memanfaatkan teknologi tepat guna untuk kebutuhan pengembangan usahanya (Sutrisno, 2011).

Pengembangan UMKM seperti yang dijelaskan di atas juga tidak lepas dari peran pemerintah dalam masalah yang dihadapi oleh UMKM (Sijabat, 2015). Saat ini banyak program dari pemerintah yang juga melibatkan akademisi untuk berperan serta dalam hal ini dengan bentuk program pengabdian masyarakat. Sebagai salah satu bentuk program pengabdian masyarakat maka muncul program kegiatan pengabdian pada masyarakat "Peningkatan Pendapatan Melalui Pengelolaan Bernilai Tambah Pada Usaha Rumahan".

\section{ARUM SNACK (Mitra 1)}

Usaha rumahan yang dilakukan oleh Sri Atun sudah digeluti sejak Februari 2016. Sri Atun sebelumnya hanya berjualan bensin di depan rumahnya di Jl.Halmahera No.30, Bareng, RT/RW : 04/05, Klaten. Berjualan bensin tidak berjalan dengan lancar maka kemudian dengan keahliannya dapat membuat makanan ringan berupa peyek kacang, teri, dan kacang ijo, Sri Atun memulai usahanya. Dengan bahan baku yang mudah diperoleh yaitu tepung terigu, tepung maizena, putih telur, dan lain-lain maka Sri Atun berproduksi membuat peyek kacang, kacang ijo dan teri.

Usaha rumahan ini dinamakan Arum Snack walaupun hanya memiliki 3 macam makanan ringan yang baru dibuat. Namun dalam rencana jangka panjang akan membuat makanan ringan lainnya. 
Produksi untuk peyek selama ini hanya dibuat setiap 2 kali dalam seminggu. Tenaga kerja yang mengerjakan adalah Sri Atun sendiri. Proses produksi yang dimulai dari membuat adonan dari beberapa campuran bahan bakunya, penggorengan serta pengemasan dilakukan sendiri. Hal ini menjadikan produksi yang dilakukan kurang maksimal. Dalam satu kali proses pembuatan dihasilkan 25-30 bungkus yang dijual dengan harga sekitar Rp. 15.000,- setiap bungkusnya.

Penjualan yang dilakukan dengan cara berkeliling di setiap rumah di daerah setempat. Hal tersebut dilakukan sendiri oleh Sri Atun dari belanja bahan baku sampai dengan proses penjualan.

Dalam usaha pembuatan makanan ringan ini ARUM SNACK mengalami permasalahan dari segi prduksi dan juga segi pengelolaan keuangan. Masalah yang dihadapi adalah sebagai berikut :

1. Permasalahan Produksi

Untuk membuat peyek kacang, kacang tanah yang digunakan sebagai bahan baku harus dibuat kecil-kecil dengan mengiris secara manual oleh Sri Atun sendiri. Karena hal tersebut yang paling banyak menggunakan waktu dalam proses produksi yaitu sekitar 5- 7 jam. Proses produksi dengan merajang (mengiris) kacang tanah mentah secara manual maka proses produksi kurang efektif dan efisien. Hal tersebut membuat proses produksi hanya bisa dilakukan 2 kali dalam seminggu.

2. Permasalahan Pengelolaan Keuangan Keuangan atau aliran uang masuk dari penjualan dan uang keluar dari proses pembelian bahan baku yang dilakukan Sri Atun sering kali mengalami kendala, dimana dia tidak dapat menghitung secara pasti perputaran modal yang digunakan dalam produksinya tersebut. Hal ini disebabkan karena Sri Atun tidak dapat memisahkan perhitungan uang untuk usahanya dan untuk kebutuhan keluarga (pribadi)

\section{YASMIN COLLECTION (Mitra 2)}

Usaha rumahan YASMIN COLLECTION adalah usaha dagang yang berjualan tas, sepatu, meja belajar, aksesoris dan baju. Usaha dirintis pertama kali dengan cara mengambil barang dagangan dari Vanqis. Dijual dengan cara tradisonal dengan tidak memiliki tempat usaha, namun barang hanya didisplay di rumahnya yang letaknya tidak strategis. Pendiri dari usaha ini adalah Ibu Yasmiati dengan alamat rumah dan tempat usaha yang sama yaitu Latar Putih, Gg. Truntum, Kelurahan Bareng, Kecamatan Klaten.

Pemasaran masih bersifat tradisional melalui HP yaitu lewat BBM. Usaha ini dimulai tahun 2014 sekitar bulan September. Usaha rumahan ini dijalankan sendiri oleh Ibu Yasmiati dari pembelian barang dagangan sampai dengan melakukan penjualannya. Meskipun demikian sebenarnya dari modal yang kecil namun usaha ini dapat menjanjikan laba yang cukup.

Usaha jual beli (dagang) yang dikelola selama ini masih belum menggunakan manajemen yang baik, sehingga mengalami kesulitan dalam pengembangan usahanya agar menjadi usaha dagang yang lebih besar. Hal ini disebabkan karena berbagai hal berikut :

1. Pemasaran dari barang dagangan masih manual dari mulut ke mulut dan sekedar menggunakan HP melalui BBM.

2. Pengelolaan usaha bisnis masih belum dapat memisahkan keuangan untuk kepentingan keluarga dengan kepentingan usaha sehingga usaha bisnis yang dirintis tidak bisa berkembang lebih baik.

Berdasarkan uraian di atas maka permasalahan yang dihadapi oleh mitra adalah:

1. Bagaimana cara agar pengirisan (proses merajang) kacang tanah mentah yang digunakan dapat lebih cepat dan tidak banyak menyita waktu produksi?

2. Bagaimana pengelolaan keuangan yang baik sehingga dapat mengetahui perputaran modal yang digunakan dalam usaha makanan ringan ini?

3. Bagaimana barang dagangan dari usaha ini bisa dipasarkan lebih luas agar pangsa pasar meningkat sehingga dapat meningkatkan omset dari usaha rumahan bisnis ini?

4. Bagaimana cara pengelolaan keuangan yang baik pada usaha rumahan ini untuk menjadi lebih profesional agar dapat berkembang lebih besar? 
Pelaksanaan kegiatan pengabdian ini bertujuan untuk :

1. Dapat meningkatkan omset mitra dengan memberikan alat pengrajang kacang agar lebih efisien dan efektif.

2. Dapat meningkatkan pengelolaan adminisitrasi usaha rumahan mitra lebih profesional sehingga usaha mitra dapat berkembang lebih besar.

3. Dapat meningkatkan omset mitra dengan memberikan keahlian memasarakan produk dari usaha rumahan mitra.

4. Dapat meningkatkan pengelolaan adminisitrasi usaha rumahan mitra lebih profesional sehingga usaha mitra dapat berkembang lebih besar.

\section{METODE}

Pelaksanaan pengabdian dengan melakukan demonstrasi pemakaian alat pengrajang, pemasaran online dan pembuatan adminitrasi usaha kecil dengan membuat aliran kas usaha yang sederhana. Pendampingan dan monitoring juga dilakukan untuk memperoleh hasil yang diinginkan sesuai tujuan dari pengabdian yaitu peningkatkan omset dari mitra.

\section{A. ARUM SNACK (Mitra 1)}

Program IbM yang dilaksanakan yaitu dengan kegiatan sebagai berikut:

1. Membuat alat pengrajang kacang tanah sebagai bahan baku dari pembuatan peyek kacang.

2. Melakukan pendampingan dalam penggunaan mesin tersebut kepada mitra dalam proses produksinya.

3. Pendampingan pengelolaan keuangan dilakukan agar dapat menunjukkan kepada mitra bagaimanna manajemen usaha yang baik dan dapat melihat perputaran modal dan laba yang diperoleh yang dapat digunakan sebagai bahan pertimbangan dalam pengembangan usahanya.

\section{B. YASMIN COLLECTION (Mitra 2)}

Pelaksanaan IbM dengan mitra ke 2 ini dengan kegiatan sebagai berikut :

1. Pengenalan manajemen dan pengelolaan keuangan sederhana pada bisnis dagang yang dilakukan secara online tidak hanya melalui media sosial seperti yang sudah dilakukan.
2. Pendampingan pengelolaan bisnis online yang diarahkan ke bisnis yang profesional.

3. Pengenalan pemasaran secara online

4. Pendampingan pengelolaan keuangan sederhana

\section{HASIL DAN PEMBAHASAN}

Kegiatan pengabdian yang dilaksanakan bertujuan untuk menghasilkan output yang direncanakan, yaitu perbaikan dari pengelolaan produksi, pemasaran yang profesional dan pengelolaan usaha yang lebih baik sehingga usaha mikro dari mitra dapat meningkat pendapatannya dan mampu bersaing dalam pasar. Kegiatan pengabdian secara riil dengan membuatkan alat produksi dan memberikan sarana untuk dapat memperluas jangkauan pemasaran disamping kegiatan pemberian muatan materi pelatihan untuk pengelolaan usaha yang lebih baik.

Kegiatan pengabdian seperti yang pernah dilakukan terlihat bahwa kemajuan teknologi dapat meningkatkan produktivitas dan kualitas produk dari kegiatan UMKM (Sutrisno, 2011). Hal itu juga termasuk dalam kegiatan belanja yang sekarang lebih disukai konsumen yaitu dengan menggunakan toko online, sehingga pengelola toko juga menggunakan Facebook dan jejearing sosial dalam memasarankan barang dagangannya (Juanita, 2011).

\section{A. ARUM SNACK (Mitra 1)}

Dalam meningkatkan produktivitas dan kualitas dalam pembuatan peyek kacang maka pembuatan mesin pengrajang kacang dilakukan oleh pengabdi. Mesin ini dirancang dengan menggunakan penggerak motor berbahan bakar bensin. Hal ini dilakukan (tidak dengan menggunakan listrik) karena saat ini tarif listrik lebih mahal dan kapasitas listrik rumah dari mitra tidak mencukupi. Mesin ini diharapkan lebih efisien dan efektif dengan menggunakan mesin dengan penggerak motor.

Mesin ini dapat meningkatkan produktivitas yaitu pengrajangan kacang yang biasanya sebanyak $15 \mathrm{~kg}$ dalam waktu 7 jam maka proses ini hanya memerlukan waktu sekitar 1 jam dengan tidak banyak menggunakan tenaga manusia sehingga dapat melakukan proses produksi lainnya seperti 
membuat adonan, menggoreng, maupun mengemas.

Hal ini dapat mempersingkat waktu produksi yang biasanya 2 kali dalam seminggu dapat meningkatkan produktivitas menjadi 4 kali dalam seminggu. Dalam pemasaran mitra ini dibantu oleh mitra 2 (Yasmin Online Shop) dengan penawaran lewat online. Sehingga ada peningkatan penjualan.

Untuk administrasi usaha, mitra baru melakukan pemisahan pengelolaan uang kas usaha dengan rumah tangga dengan menggunakan buku kas secara manual karena keterbatasan dari pengelola yang buta huruf.

Hal ini dapat dijelaskan dalam tabel berikut ini :

\begin{tabular}{|l|l|l|}
\hline \multicolumn{1}{|c|}{ Keterangan } & \multicolumn{1}{c|}{ Sebelum } & \multicolumn{1}{c|}{ Sesudah } \\
\hline Proses Merajang & 7 jam & 1 jam \\
\hline Produktivitas & $2 \mathrm{kali} / \mathrm{minggu}$ & $4 \mathrm{kali} / \mathrm{minggu}$ \\
\hline Penjualan & Rp. $3.600 .000,-$ & Rp. $6.000 .000,-$ \\
\hline Laba & Rp. $1.200 .000,-$ & Rp. $2.000 .000,-$ \\
\hline
\end{tabular}

\section{B. YASMIN COLLECTION (Mitra 2)}

Mitra ke 2 yang memiliki usaha penjualan lewat media sosial dengan menggunakan HP merasa memiliki keterbatasan dalam pemasarannya yang kurang luas. Kebutuhan akan laptop untuk menunjang pemasarannya dengan menggunakan pemasaran melalui blogger dan facebook dirasa oleh mitra akan dapat meluaskan pangsa pasarnya.

Melalui berbagai pertimbangan, kami berupaya membuatkan blog dan facebook untuk penjualan secara online. Sebagai hasil pengembangan bisnis yang sebelumnya hanya berjualan online koleksi tas, sepatu dan pakaian. dengan adanya kerjasama dengan mitra 1 (Arum Snack) maka mitra 2 turut menjual secara online hasil produksi dari mitra 1. Namun tidak hanya makanan ringan dari mitra 1 saja namun mitra 2 juga kemudian mengembangakn penjualan onlinenya dengan menawarkan makananmakanan ringan yang mecirikan makanan khas dari Klaten, seperti paru goreng, kulit dan cakar goreng, rengginang, pare goreng dan lain sebagainya. Dalam perkembangannya toko online yang dibuat bernama "YASMIN ONLINE SHOP".

Lokasi mitra dekat dengan sentra industri makanan ringan maka tidak terbuka kesempatan bagi mitra untuk dapat memperoleh barang dagangan yang dijual melalui online. Hal yang diajarkan oleh pengabdi yaitu melakukan pembelian dalam jumlah yang cukup banyak dari masingmasing jenis makanan, kemudian dilakukan pengemasan dengan menggunakan merk "YASMIN CEMILAN KLATEN", kemudian ditawarkan secara online di blog dan facebook yang telah dibuatkan oleh pengabdi.

Ternyata lebih banyak diperoleh order dari konsumen yang berlokasi diluar kota Klaten. Data terakhir menunjukkan pengiriman makanan khas Kota Klaten sampai sampai ke Kalimantan. Hasil program kegiatan pada mitra dapat disimpulkan sebagai berikut :

\begin{tabular}{|l|l|l|}
\hline Keterangan & \multicolumn{1}{|c|}{ Sebelum } & \multicolumn{1}{|c|}{ Sesudah } \\
\hline $\begin{array}{l}\text { Jualan } \\
\text { Juan media } \\
\text { sosial }\end{array}$ & $\begin{array}{l}\text { Laptop online } \\
\text { medsos dan } \\
\text { blogger }\end{array}$ \\
\hline $\begin{array}{l}\text { Luas } \\
\text { Produk }\end{array}$ & $\begin{array}{l}\text { Koleksi } \\
\text { Fashion }\end{array}$ & $\begin{array}{l}\text { Fashion, } \\
\text { makanan ringan } \\
\text { khas Klaten }\end{array}$ \\
\hline Luas Pasar & Klaten & $\begin{array}{l}\text { Jawa Tengah } \\
\text { bahkan sampai } \\
\text { Kalimantan }\end{array}$ \\
\hline Penjualan & $\begin{array}{l}\text { Rp. } \\
1.500 .000,- \\
\text { / bulan }\end{array}$ & $\begin{array}{l}\text { Rp. 3.500.000,/ } \\
\text { bulan }\end{array}$ \\
\hline Pendapatan & $\begin{array}{l}\text { Rp. } \\
300.000,-/ \\
\text { bulan }\end{array}$ & $\begin{array}{l}\text { Rp. 600.000,-/ } \\
\text { bulan }\end{array}$ \\
\hline
\end{tabular}

\section{SIMPULAN}

Kesimpulan dari program kegiatan pengabdian yang telah dilakukan adalah sebagai berikut :

1. Kegiatan pengabdian pada mitra 1 (Arum Snack) dan mitra 2 (Yasmin Collection) telah terlaksana dengan lancar yaitu melakukan perbaikan proses produksi pada mitra 1 dan pengembangan pemasaran online pada mitra 2.

2. Pembuatan mesin pengrajang kacang dapat meningkatkan produktivitas dan pendapatan mitra 1 .

3. Pembuatan blog dan facebook sebagai media online pemasaran untuk mitra 2 juga telah jadi.

4. Monitoring dan evaluasi akan dilakukan untuk kedua mitra agar dapat tetap melakukan kegiatan usaha secara efektif dan efisien. 


\section{DAFTAR PUSTAKA}

Hamdani, A. H., \& Awatara, I. G. P. D. (2011). Faktor-Faktor Yang Mempengaruhi Upgrading Umkm Di Kota Surakarta. Prosiding Seminar Nasional 4th UNS SME's Summit \& Awards 2015, ("Sinergitas Pengembangan UMKM dalam Era Masyarakat Ekonomi ASEAN (MEA)), 176-183.

Juanita, S. (2011). Analisa Strategi Bisnis Penjualan Online. Proceeding Politeknik Telkom.

Rachman, A. N., Muhamad, C., Ramdani, S., Kunci, K., \& Geulis, K. (2016). IbM Pelatihan Pemanfaatan E-Commerce Sebagai Media Pemasaran Global Untuk Peningkatan Penjualan Produk Kelom Geulis ( Studi Kasus : UKM kelom geulis Tamansari Tasikmalaya). Jurnal Siliwangi Vol . 2 No . 1 Mei 2016 Seri Pengabdian Pada Masyarakat ISSN 2477-6629, 2(1), 64-68.

Sijabat, S. (2015). Potret Iklim Usaha Pemberdayaan UMKM. Infokop, 1-17. Retrieved from http://www.jurnal.smecda.com/index.php /infokop/article/view/186

Sutrisno, J. (2011). Kewirausahaan Dan Pengembangan Teknologi UMK. Infokop Volume 19 - Juli 2011: 86 - 103, 19(April), 86-103.

Utari, T., \& Dewi, P. M. (2014). Pengaruh Modal, Tingkat Pendidikan Dan Teknologi Terhadap Pendapatan Usaha Mikro Kecil Dan Menengah (Umkm) Di Kawasan Imam Bonjol Denpasar Barat. Ekonomi Pembangunan, 3(12), 576-585. 